\title{
Article \\ A Review and Categorization of Artificial Intelligence-Based Opportunities in Wildlife, Ocean and Land Conservation
}

\author{
Diane A. Isabelle ${ }^{1,2, *(D)}$ and Mika Westerlund ${ }^{1}$ (D)
}

check for updates

Citation: Isabelle, D.A.; Westerlund, M. A Review and Categorization of Artificial Intelligence-Based Opportunities in Wildlife, Ocean and Land Conservation. Sustainability 2022, 14, 1979. https://doi.org/ $10.3390 /$ su14041979

Academic Editor: Dilek Cetindamar

Received: 21 December 2021

Accepted: 28 January 2022

Published: 9 February 2022

Publisher's Note: MDPI stays neutral with regard to jurisdictional claims in published maps and institutional affiliations.

Copyright: () 2022 by the authors Licensee MDPI, Basel, Switzerland. This article is an open access article distributed under the terms and conditions of the Creative Commons Attribution (CC BY) license (https:// creativecommons.org/licenses/by/ $4.0 /)$.
1 Sprott School of Business, Carleton University, Ottawa, ON K1S 5B6, Canada; mika.westerlund@carleton.ca 2 Department of Business Management, School of Management, College of Business and Economics, University of Johannesburg, P.O. Box 524, Auckland Park, Johannesburg 2006, South Africa

* Correspondence: diane.isabelle@carleton.ca

\begin{abstract}
The scholarly literature on the links between Artificial Intelligence and the United Nations' Sustainable Development Goals is burgeoning as climate change and the biotic crisis leading to mass extinction of species are raising concerns across the globe. With a focus on Sustainable Development Goals 14 (Life below Water) and 15 (Life on Land), this paper explores the opportunities of Artificial Intelligence applications in various domains of wildlife, ocean and land conservation. For this purpose, we develop a conceptual framework on the basis of a comprehensive review of the literature and examples of Artificial Intelligence-based approaches to protect endangered species, monitor and predict animal behavior patterns, and track illegal or unsustainable wildlife trade. Our findings provide scholars, governments, environmental organizations, and entrepreneurs with a much-needed taxonomy and real-life examples of Artificial Intelligence opportunities for tackling the grand challenge of rapidly decreasing biological diversity, which has severe implications for global food security, nature, and humanity.
\end{abstract}

Keywords: artificial intelligence; Sustainable Development Goals; SDG 14; SDG 15; wildlife; ocean conservation; land conservation; biodiversity; mass extinction; robotics; 4IR

\section{Introduction}

Advances in Artificial Intelligence (AI) and supporting digital technologies have opened the door to the application of AI-enabled systems to tackle global challenges. As such, AI holds great promise to accelerate many of the United Nations' Sustainable Development Goals [1,2]. In 2015, all United Nations Member states adopted the 2030 Agenda for Sustainable Development, a blueprint for peace and prosperity for people and the planet. The agenda encompasses 17 Sustainable Development Goals (SDGs) with 169 targets to end poverty and hunger, and strategies to improve health, education, spur economic growth, while tackling climate change and preserving oceans and forests [3] in all countries, regardless of their actual development status [4]. Great progress has been achieved in some of the goals, in particular goals related to primary health and education [5]. Of significant concern though are goals where progress is more challenging due to complex systemic global issues such as climate change, ocean health, and biodiversity loss, and for which time to address them is running out [5].

Considering this situation, the focus of our research is on two specific environmentrelated SDGs: SDG 14, Life below Water, and SDG 15, Life on Land. The goal of SDG 14 is to "conserve and sustainably use the oceans, seas and marine resources for sustainable development", while the goal of SDG 15 is to "protect, restore and promote sustainable use of terrestrial ecosystems, sustainably manage forests, combat desertification, and halt and reverse land degradation and halt biodiversity loss" [3]. At this time, these two SDGs are languishing at the bottom of priorities by industry and countries alike and are not receiving the attention they require [6]. Yet, these goals are very relevant for many sectors, not to mention humanity-hence, the impetus for our research. 
The scholarly literature on the links between AI and the United Nations' Sustainable Development Goals (SDGs) is burgeoning. On the one hand, AI is believed to contribute technological solutions and breakthroughs to advance the UN's SDGs $[1,4,7,8]$. On the other hand, studies have shown the unintended consequences of AI [1,7], particularly related to societal impacts, reduced inequalities (SDG 10) [9] and ethical considerations [10]. Despite these unintended consequences being worthy of further research, our work concentrates on AI's positive current and potential contributions to SDGs 14 and 15.

Previous scholarly work has investigated AI-enabled technologies to all SDGs. Among them, Palomares et al. [4] conducted a SWOT analysis of AI technologies to determine whether they act as facilitators or barriers to each of the SDGs. Vinuesa et al. [7] investigated the positive and negative impacts of AI on the SDGs and identified important aspects that are currently overlooked in research. Sætra [1] broadened the investigation of AI and SDGs by factoring in a larger context, interlinkages, and AI's ethical implications and sustainability to avoid AI hype. Other studies have investigated specific aspects of AI related to SDGs such as global governance, policy perspectives, the role of business, ethics, knowledge spillovers, Green AI, AI in Industry 4.0, and environmental, social, and governance (ESG)-related impacts of AI, among others [8,9,11-18].

Despite this wealth of AI knowledge, our review of the literature since the adoption of the UN SDGs did not reveal previous work related to the categorization of AI approaches and opportunities specifically related to SDGs 14 and 15. This is deeply concerning and a critical research gap. Without a strong understanding and an organization of AI avenues of solution to SDGs related to the environment such as SDGs 14 and 15, the research risks being disjointed. Furthermore, with less than ten years to deliver the SDGs by 2030dubbed the "decade of action" [5,6]-concerted and cooperative efforts from governments, private and public sector organizations are urgently needed.

The purpose of our study is not to provide an exhaustive and all-encompassing literature review of this extensive field, but rather to investigate the extant academic and practitioner literature and propose a conceptual framework to categorize AI opportunities for various domains of wildlife, ocean and land conservation. Of note, the study does not focus on any specific type of $\mathrm{AI}$, but rather explores the variety of options in the conservation context.

This study is one of the pioneers that discusses the role of AI technologies in SDGs 14 and 15 specifically and provides a conceptual framework to guide future research. The framework can be built upon for further exploration as its application is largely transferable to other SDGs. Moreover, we support Sætra's conclusion [17] that there is a need to go beyond simplistic analyses of AI applications per specific SDG. Hence, the framework can be used to further investigate the deterioration of natural habitat and decrease in biological diversity - that is, the biotic crisis leading to mass extinction of species. Our findings provide scholars, governments, environmental organizations, and entrepreneurs with a much-needed taxonomy and examples of AI opportunities for tackling these grand challenges that have severe implications for global food security, nature, and humanity.

\section{SDGs 14 and 15 and Related Targets}

The 17 SDGs can be organized into three main dimensions: economic, social, and environmental [4]. Under the environmental dimension, the natural environment comprises three SDGs: SDG 13, Climate Action; SDG 14, Life below Water; and SDG 15, Life on Land [4]. In this study, our focus is on SDGs 14 and 15, addressing marine and land life. This section summarizes the two SDGs of interest and provides a brief overview of AI along with the status of AI in the achievement of those SDGs.

\subsection{SDG 14-Life below Water}

SDG 14, Life below Water, aims to "conserve and sustainably use the oceans, seas and marine resources for sustainable development" [19]. More than three billion people rely on the ocean for their livelihoods, and over 80 percent of world trade is transported by sea [19]. 
Ocean activity has increased by 26 percent since pre-industrial levels and is expected to increase by a further 125 percent during the current century [5].

However, the sustainability of oceans is under severe threat due to human activities. Rising CO2 emissions, acidification and deoxygenation, overfishing, and land-based pollutants lead to long-term repercussions requiring urgent actions to protect marine environments, invest in ocean science, and support small-scale fishing communities as well as sustainably manage the oceans [19]. The chemistry of the oceans is changing faster than at any point in 300 million years, resulting in acidification and rising temperatures of oceans [20]. Every year, some 8 million tons of plastic - and their toxins-enter the oceans [21]. Coastal areas are home to nearly 40 percent of the world's population. These areas face growing risks from eutrophication-that is, excess nutrient loading into coastal environments resulting from human activities Fertilizer run-off, livestock waste, sewage discharge, aquaculture and atmospheric nitrogen emissions are the main drivers of eutrophication [19]. Coral reefs are increasingly at a risk of collapse due to global heating and overfishing, resulting in a loss of coastal protection from sea-level rise, and impacts on tourism and fisheries [22]. Living coral has declined by half globally since the 1950s, resulting in some 60 percent of coral-reef-associated biodiversity [22]. Over half of marine key biodiversity areas are not protected. Further, "dead zones" - areas of water that lack sufficient oxygen to support marine life-are rising at an alarming rate [19,20]. The Second World Ocean Assessment report from the United Nations notes that the understanding of the ocean is continuing to improve. However, human activities continue to degrade the ocean. Furthermore, a lack of quantification of the impacts of pressures and their cumulative effects on ocean remains [23,24].

Of particular concern is the low level of funding for marine research, particularly compared to the oceans' enormous economic contribution. Marine research requires expensive research vessels and specially designed advanced technologies and equipment. It is also logistically challenging. Still, the proportion of gross domestic expenditure on ocean science is smaller than that of other major fields of research [19]. Adding to these constraints, COVID-19 has led to dramatic reductions in ocean observations and the full impact of the pandemic on ocean science is still unknown [19]. That said, target 14.a, i.e., "increase scientific knowledge, research, and technology for ocean health", aims to address these challenges.

The UN has defined seven key targets for SDG 14 (14.1 through 14.7) and three additional targets (14.a, 14.b and 14.c) for resource mobilization and policy to be achieved by 2030 [25]. These targets are described in Table 1.

Table 1. Summary of SDG 14 targets $[25,26]$.

\begin{tabular}{|c|c|}
\hline Target & Summary \\
\hline 14.1 & Prevent and significantly reduce marine pollution \\
\hline 14.2 & Sustainably manage and protect marine and coastal ecosystems \\
\hline 14.3 & Minimize and address the impacts of ocean acidification \\
\hline 14.4 & $\begin{array}{l}\text { Effectively regulate harvesting and end overfishing, illegal, unreported and unregulated } \\
\text { fishing and destructive fishing practices and implement science-based } \\
\text { management plans }\end{array}$ \\
\hline 14.5 & Conserve at least 10 percent of coastal and marine areas \\
\hline 14.6 & Prohibit certain forms of fisheries subsidies \\
\hline 14.7 & $\begin{array}{c}\text { Increase the economic benefits to Small Island developing States and least developed } \\
\text { countries from the sustainable use of marine resources }\end{array}$ \\
\hline 14.a & Increase scientific knowledge, develop research capacity, and transfer marine technology \\
\hline 14.b & Provide access for small-scale artisanal fishers to marine resources and markets \\
\hline 14.c & $\begin{array}{l}\text { Enhance the conservation and sustainable use of oceans and their resources by } \\
\text { implementing international law }\end{array}$ \\
\hline
\end{tabular}

Aiming to reach the targets includes setting and measuring key indicators, along with the drafting and implementation of international legal and institutional frameworks. 
The achievement of "Life below Water" goal and targets are measured by a set of key indicators [25].

\subsection{SDG 15-Life on Land}

SDG 15, Life on Land, aims to "protect, restore and promote sustainable use of terrestrial ecosystems, sustainably manage forests, combat desertification, and halt and reverse land degradation and halt biodiversity loss" [27]. Terrestrial ecosystems are critical to all aspects of human life, considering that over 80 percent of the human diet is provided by plants [28]. However, human-influenced drivers are causing unprecedented shifts and degradation of terrestrial ecosystems [29].

Forests are biodiverse ecosystems, providing habitats to over four-fifths of all terrestrial species, as well as sources of clean air and water [29]. The UN reports that progress to safeguard key biodiversity areas has stalled over the last five years [27]. The planet is losing its biodiversity at "mass extinction" rates: species' populations have declined by around 60 percent since 1970 [20]. The risk of species extinction has worsened by almost 10 percent in the past 25 years alone [5]. Further, an estimated 1.6 billion people depend on forests for their livelihood [29], and forests are home to more than 80 percent of all terrestrial species of animals, plants and insects [28]. Forests act as carbon sinks by absorbing about two billion tons of carbon dioxide per year [2]. Yet, current deforestation rates could lead to a drop in rainfall, triggering wider consequences for the Earth's atmospheric circulatory systems [20]. Although progress has been made towards sustainable forest management, the world has lost 100 million hectares of forest over the last 20 years [27]. Desertification and land degradation affect over half of the land used for agriculture globally. Land degradation disproportionately affects the global poor [28,29]. On a more positive note, almost all countries have adopted legislation for preventing or controlling invasive alien species. These alien species negatively affect native biodiversity [27].

The UN has defined nine key targets for SDG 15 (SDG 15.1 through 15.9) and three additional targets (15.a, 15.b and 15.c) for resource mobilization and policy to be achieved by 2030, described in Table 2 below [30].

Table 2. Summary of SDG 15 targets [28,30].

\begin{tabular}{|c|c|}
\hline Target & Summary \\
\hline 15.1 & $\begin{array}{c}\text { Ensure the conservation, restoration and sustainable use of terrestrial and } \\
\text { inland freshwater ecosystems and their services }\end{array}$ \\
\hline 15.2 & $\begin{array}{c}\text { Promote the implementation of sustainable management of all types of forests, } \\
\text { halt deforestation, restore degraded forests }\end{array}$ \\
\hline 15.3 & Combat desertification, restore degraded land and soil \\
\hline 15.4 & Ensure the conservation of mountain ecosystems \\
\hline 15.5 & $\begin{array}{c}\text { Take urgent and significant action to reduce the degradation of natural } \\
\text { habitats, halt the loss of biodiversity, protect and prevent the extinction of } \\
\text { threatened species }\end{array}$ \\
\hline 15.6 & $\begin{array}{c}\text { Promote fair and equitable sharing of the benefits arising from the utilization } \\
\text { of genetic resources }\end{array}$ \\
\hline 15.7 & $\begin{array}{l}\text { Take urgent action to end poaching and trafficking of protected species of flora } \\
\text { and fauna }\end{array}$ \\
\hline 15.8 & $\begin{array}{l}\text { Introduce measures to prevent the introduction and significantly reduce the } \\
\text { impact of invasive alien species on land and water ecosystems }\end{array}$ \\
\hline 15.9 & Integrate ecosystem and biodiversity values into national and local planning \\
\hline 15.a & $\begin{array}{l}\text { Mobilize and significantly increase financial resources from all sources to } \\
\text { conserve and sustainably use biodiversity and ecosystems }\end{array}$ \\
\hline $15 . b$ & $\begin{array}{c}\text { Mobilize significant resources from all sources and at all levels to finance } \\
\text { sustainable forest management }\end{array}$ \\
\hline 15.c & $\begin{array}{c}\text { Enhance global support for efforts to combat poaching and trafficking of } \\
\text { protected species }\end{array}$ \\
\hline
\end{tabular}


As for all of the SDGs, the achievements of the Life on Land goal and targets are measured by a set of key indicators [30].

\subsection{Overview of Artificial Intelligence}

Artificial Intelligence (AI) is generally defined as the intellect expressed by computer systems-as opposed to human intelligence-that can sense their environment, think, learn, and act [31]. Its definition has evolved over time and is further divided into two types: artificial narrow intelligence (ANI), which includes all current AI-that is, AI applications developed for a particular task, such as Google search; and artificial general intelligence (AGI), which remains theoretical but is rapidly becoming feasible with the proliferation of applications [9]. AGI encompasses machines with abilities to reach and pass human intelligence, for instance autonomous cars [32] that are increasingly capable of performing complex intellectual tasks similarly to humans. In the context of the SDGs, the United Nations defines AI as an ensemble of advanced technologies that enable "machines capable of imitating certain functionalities of human intelligence, including such features as perception, learning, reasoning, problem solving, language interaction, and even producing creative work" [10].

$\mathrm{AI}$ is not a new phenomenon, given that the term "artificial intelligence" was first coined in 1955 [4]. However, technical advances have allowed a more rapid progress in recent years [10]. Despite this progress, $\mathrm{AI}$ is still in its infancy, and its evolution is therefore challenging to predict [8]. That said, AI has reached a stage of development and widespread application that provides hope for its contribution to achieving the SDGs $[4,15]$.

Essentially, AI accomplishes complex goals by collecting data from its environment and processing that data to learn the way to achieve the goal it was designed for. Hence, the main elements of an AI system are: (1) computational system, i.e., software or hardware that can process data through algorithms, (2) data, and (3) end goal [4]. An AI system requires the following skills $[4,31,33]$.

Knowledge representation: input data represented in a specific format that can be stored and processed.

Natural language processing: algorithms that process human language input and convert it into understandable representations.

Computer vision/image analytics: pull of relevant information from images for advanced classification and analysis.

Machine learning: learning algorithms to work with extremely large datasets, capacity to extrapolate patterns, adapt to new scenarios, and to learn from examples, and deep learning, a subset of machine learning, that constructs artificial neural networks to mimic the structure and function of the human brain.

Automated reasoning: capacity to perform specific actions based on input data and information/knowledge stored.

Major AI disciplines focus on endowing AI systems with the capacity for reasoning and decision making, and for learning, based on input data. AI systems learn by processing known examples and observations [4]. As such, machine learning is a family of techniques for AI systems to learn and adapt without following explicit instructions, by using algorithms and statistical models to analyze and draw inferences from patterns in data [24]. Basic types of machine learning include (i) supervised learning (learning based training data), (ii) unsupervised learning (learning relies on the machine to seek patterns by finding similarities on non-annotated data), and (iii) reinforcement learning (based on an iterative process of rewarding and punishing the algorithm to learn a specific task) [4].

According to a recent report by $\mathrm{PwC}$, there are various forms of $\mathrm{AI}$ intelligence today, namely automated, assisted, augmented, and autonomous intelligence [31]. While assisted and augmented intelligence differ in terms of representing hardwired versus adaptive systems, both keep humans in the loop. Automated and autonomous intelligence also differ in terms of adaptivity, but do not necessitate human assistance and replace human routines and tasks with computing power. 
Indeed, AI often requires other digital technologies to complement data acquisition, processing, storage and communications, and interaction to perform required tasks. These so-called Fourth Industrial Revolution (4IR) technologies include blockchain, Internet of Things (IoT), 3D technologies, 5G communication infrastructure, Big Data, augmented/virtual reality (AR/VR), and emerging technologies, such as quantum computing and generic engineering, that have not yet reached their maturity but will be transformative [4,5]. Recently, Mabkhot et al. [14] investigated the extent to which 4IR technologies contribute to each of the SDGs. Among 4IR technologies, Big Data and analytics are strong contributors to all of the SDGs, but the influence of 4IR on SDGs 14 and 15 is generally weaker than for other SDGs $[5,14]$.

AI-driven robotics are also part of the AI landscape, addressing smart machines with the capacity to act and move in the physical world. For example, more drones are now enabled by robotics, able to fly without a pilot and operate autonomously [5]. Most innovations related to AI are a combination of existing and new technology. For example, AI + sensors + big data + drones = precision monitoring [5]. Self-driving cars or autonomous vehicles are other examples of AI-driven robotics: they must learn from their input data, and deal with the uncertainty and complexity to determine the most optimal ways to complete a journey [4]. Autonomous vehicles are the results of combining sensors + robotics $+\mathrm{AI}+5 \mathrm{G}[5]$. For AI systems in general, and to accelerate the realization of SDGs, they must be trusted by people; in other words, these systems must be robust, lawful, and ethical, referred to as "trustworthy AI systems" [4,34]. Emerging technologies such as blockchains can help improve trust in applications such as fisheries [24].

The World Economic Forum and the multinational consulting firm PwC estimate that advanced and emerging technologies under the umbrella of Fourth Industrial Revolution (4IR) technologies, or Industry 4.0, which includes AI, blockchain, Internet of Things, 5G and drones, could accelerate progress towards over two-third of SDGs [5]. As evidence of the unprecedented speed and scale of AI technologies in the economy, estimates suggest that AI could increase global GDP by nearly USD 16 trillion by 2030 [31]. That said, inequalities abound. Economic and environmental gains of tackling environmental challenges with AI technologies would predominantly be captured by Europe, East Asia and North America due to these regions' current digital readiness and levels of technology adoption, while Latin America and Sub-Saharan Africa would stand to gain the least [20]. Hence, there is an opportunity and an urgent need to strengthen innovation capacity globally to accelerate SDG progress, taking into consideration the concept of inclusive innovation to reduce the inequality-increasing effects of innovation [35].

\subsection{Artificial Intelligence and SDGs}

A recent $\mathrm{PwC}$ report has mapped some 345 technology applications across the SDGs, as a representation of the most prominent innovations. The report summarizes these technologies and their level of maturity (low, medium, high) for SDGs 14 and 15. For example, high-maturity AI technologies include aquatic or land habitat monitoring, detection, and analytics, while low-maturity technologies include genome modification and advanced nanorobotics [36]. However, the report notes that emerging solutions (low maturity) could still outperform mature solutions over the coming decade to 2030, if the enabling environment is supportive, and/or the solution has a large market and high disruptive capability [36]. Currently though, the World Economic Forum [5] notes that many emerging solutions are nascent, with a focus on commercial market gains rather than achieving global goals. These promising solutions will likely be unable to move past the concept or demonstration stages without an enabling and supportive environment that values broader environmental and social goals.

\section{Methods and Search Strategies}

We conducted a comprehensive and interdisciplinary literature review to identify the connections between AI and SDGs, with a focus on SDGs 14 and 15. Specifically, we 
examined both the academic and practitioner literatures to ascertain the state of knowledge of AI practices and opportunities to positively contribute to the achievement of these two SDGs. The aim of this literature search is to develop a categorization framework of academic and emerging practices in AI-based approaches in wildlife and land conservation. From that framework, we identify research gaps and propose avenues for future investigations.

Similarly to Sætra [1], this study contains a theoretically based development of a framework to describe AI as a general scientific field and as more specific AI applications for SDGs 14 and 15. This means that we are using the existing scholarly research on AI and the SDGs, with a direct focus on SDGs 14 and 15. We supplemented this analysis by examining recent related $\mathrm{AI}$ and SDGs reports from reputable international organizations such as the United Nations, World Economic Forum, and OECD, among others, along with reports from world leader multinational professional service providers such as PwC and Deloitte. As the United Nations member states adopted the SDGs in 2015, our literature review has primarily concentrated on the most recent developments since 2019.

We note that our aim is not to conduct a formal systematic literature review but rather to approach our work from a narrative literature review perspective. Whereas systematic reviews are best suited to addressing highly structured and specific research questions, the goal of a narrative literature review is to examine important topics, describe the current state in focused areas of inquiry, advance theory development, propose directions for research, and focus and shape research questions. Baumeister and Leary [37] note that narrative literature reviews can tackle broader and more abstract questions and are particularly useful for linking together many studies to note their connections. Thus, this type of review can serve to inform the field and propose ways forward. However, narrative reviews have been criticized as having potential problems, arising mainly from the fact that narrative reviews need not be exhaustive in literature selection. The main limitations arise from the possibility of selection biases that can lead to erroneous conclusions [38]. To mitigate these potential issues, our review of the research literature drew processes for literature selection from previously published systematic reviews and supplemented the process by identifying a research area, identifying inclusion criteria, and selecting studies that meet the criteria. Of note, our study does not focus solely on a specific industry or literature stream, instead aiming at investigating the broader role of AI to our selected targets under SDGs 14 and 15. We organized our review of the literature in four phases as shown in Figure 1.

Phase 1 focused on reviewing scholarly work for systematic literature reviews of AI related to SDGs. The scholarly literature on the links between AI technologies and the SDGs is burgeoning. In this first phase, we identified recent literature reviews related to AI and SDGs to ascertain the state of the academic literature in this field. To do so, we conducted a search of recent literature reviews using Google Scholar. The search yielded only a few academic literature reviews specifically addressing aspects of AI and SDGs [4,7,8]. We summarize the reviews as below.

Palomares et al. [4] conducted a comprehensive literature review and found 869 articles that discuss the application of AI and digital technologies to the SDGs. These articles were then classified by SDG targets. Of these 869 articles, only 45 and 43 articles were related to SDG 14 and 15, respectively. The authors offer a comprehensive panoramic view of AI technologies for achieving the SDGs, along with a SWOT analysis of AI-driven technologies as facilitators or barriers for each of the SDGs [4]. They note the important contribution of AI-based technologies in achieving the SDGs. Nonetheless, they stress the need for a symbiotic relationship between $\mathrm{AI}$ and various digital technologies, the importance of the undergoing digital transformation in the development of the SDGs, and the need for high-quality, open and large-scale data infrastructures, since AI systems are fueled by big data.

Vinuesa et al. [7] categorized the 17 SDGs into Society, Economy and Environment Groups, and demonstrated the positive impacts of AI on 134 targets across all the goals but a negative impact for 59 targets across all the goals, based on published evidence of AI serving either as an enabler or an inhibitor of the SDGs [7]. The authors looked at 
the role of $\mathrm{AI}$ in achieving the SDGs and found many examples of $\mathrm{AI}$ applications to the environment goals (SDGs 13, 14, and 15). They highlight the imperative to develop the necessary regulatory insight and oversight for AI-based technologies to enable sustainable development and to determine the ethical standards that AI-based technology should be subjected to.

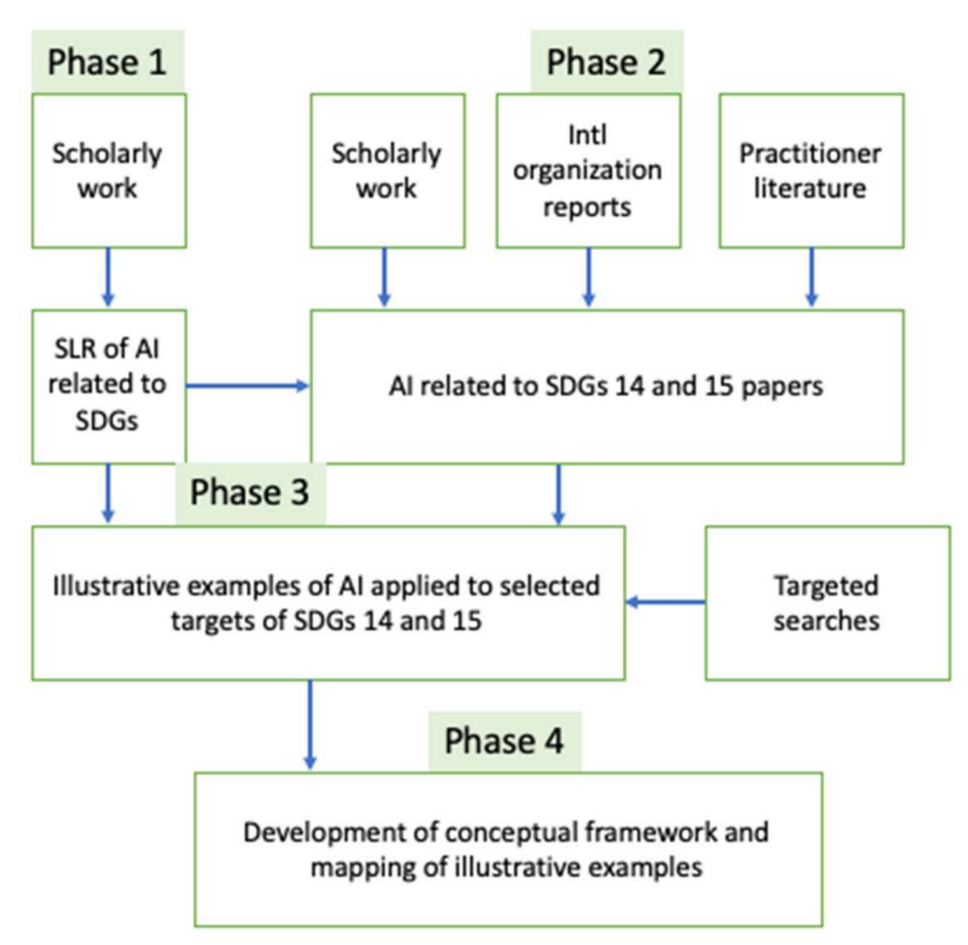

Figure 1. Search strategies.

Finally, Di Vaio et al. [8] conducted a systematic literature review of studies on AI and sustainable business models in light of SDGs, during the period 1990-2019, which yielded 73 articles. The authors found that the role of $\mathrm{AI}$ in the development of such sustainable business models from the perspective of the SDGs is not well explored in the literature [8].

Next, phase 2 comprised a review of scholarly and practitioner work for AI articles related to SDGs 14 and 15. In this second phase, we relied on Scopus database consultation, Google Scholar, and manual retrieval of articles from references of various scholarly and practitioner work to investigate the present state-of-the art literature on the role of $\mathrm{AI}$ in tackling SDGs 14 and 15 specifically. We chose a period of 2015 to 2021 inclusively, since the UN adopted the SDGs in 2015.

Thereafter, phase 3 included a selection of illustrative examples of AI applied to SDGs 14 and 15. Illustrative examples of application of AI to selected targets of SDGs 14 and 15 were chosen for their direct relevance to a target, from a credible source, and generally no older than three years. Care was taken to identify illustrative examples for every selected target of SDGs 14 and 15.

Finally, phase 4 consisted of the development of a framework and mapping of illustrative examples. In this last phase of the work, we developed a conceptual framework that best represents findings from the previous three phases and mapped the selected illustrative examples onto the framework.

\section{Results}

The illustrative examples are not intended to be exhaustive, but to be representative of recent applications of AI-enabled technologies in connection with SDGs 14 and 15. They are valuable for our intended purpose of proposing an organizing framework to help grasp the extent of current and emerging AI-enabled applications and identify opportunities. 


\subsection{Real-Life AI Applications to Achieve SDG 14-Life below Water}

The ocean is the largest ecosystem on the planet, covering two-thirds of the earth's surface and containing 97 percent of the planet's water [19]. The ocean supports life, produces more than 50 percent of the oxygen we breathe, moderates the climate, facilitates global trade and energy production, provides food, energy, water, jobs and economic benefits, and supports tourism $[19,39,40]$. However, human activities have inflicted a massive decline in ocean health, yet our reliance on the ocean ecosystem is likely to increase. As indicated by interrelated goal and targets of SDG 14, significant challenges must be addressed, all of which require data. Fortunately, concerted efforts have led to the availability of large datasets to improve global-scale ocean governance and assess the effectiveness of policies [41]. That said, Palomares et al. [4] point out the dearth of intelligent monitoring and management systems in the least developing countries, which accentuates problems related to illegal fishing, dumping and ocean pollution.

The application of AI and machine learning approaches for SDG 14 is contributing to better monitoring of illegal, unregulated and unreported catches, improving traceability of products, reducing wastage in supply chains and improving the monitoring of movements of fishing fleets, among others [23].

\subsubsection{Target 14.1 Reduce Marine Pollution}

Marine litter and plastic pollution are another threat to marine ecosystems and biodiversity [42-44]. Several AI-based applications have been developed to automatically detect, classify, and quantify floating marine litter in aerial images to help monitor and assess the environmental threat $[43,44]$, including remote sensing technologies combined with machine learning algorithms, unmanned aerial systems (UAS) and satellite imagery [44].

Example 1: MARLIT is a floating marine waste detection web app that operates on an algorithm with deep learning capabilities. The system uses AI to learn from some 4000 aerial images of the coast around Catalonia to identify the presence, density, and distribution of waste, rather than by direct observations owing to the sheer scale of the data. The deep learning techniques of the system's open access algorithm, boosted by artificial neuronal networks, automate the quantification and categorization of marine litter. Upcoming improvements to MARLIT include adapting it for use with remote sensors, which could then enable it to be used with drones as part of a fully automated process [45].

Plastic and microplastic debris do not all float but are instead collecting at the bottom of the ocean. The largest patch of such debris is the Great Pacific Garbage Patch, covering 1.6 million square kilometers with its 80,000 tons of plastic waste [25,33]. Autonomous and real-time AI systems are used to map marine debris, with results disseminated through open-source maps [33]. Other AI-based systems tackle the removal of marine debris either from the ocean or by collecting it at the source, i.e., from the rivers [33].

Example 2: Ocean Cleanup, a Dutch company, has developed an AI-based ocean cleaning system that uses algorithms to identify the optimal deployment location to collect the garbage. Real-time telemetry monitors the health and functioning of the system [46].

Example 3: Researchers in the Czech Republic have developed self-propelled microrobots that can swim, attach to plastics, and break them down. This proof-of-concept study could pave the way toward systems that can capture and degrade microplastics [47].

A crucial role of the ocean is that of climate regulation, which requires a better understanding of the ocean and the seafloor. However, less than 10 percent of the seafloor has been mapped and at depths of less than $4000 \mathrm{~m}$ [33]. A stronger understanding of the impact of human activities and effects of climate change on climate regulation from the ocean is needed. AI can provide faster and better data collection and analysis [33].

\subsubsection{Target 14.2 Protect and Restore Ecosystems}

This target aims to sustainably manage and protect marine and coastal ecosystems to avoid significant adverse impacts by strengthening their resilience and taking action for their restoration [23]. The main threats to marine ecosystems, again, come from hu- 
man activities: fishing, aquaculture, shipping, sand and mineral extraction, oil and gas exploitation, and pollution, among others [23].

Example 4: IBM has pioneered autonomous AI-powered microscopes that assess the health of plankton and share the information in the cloud. The goal is to create 3D models of plankton and monitor them in their natural environment. Microscopic plankton species are key indicators of ocean pollution levels, not to mention the base of the ocean food chain, and hence, they are quite crucial to fisheries $[40,48]$. This technology is being explored to provide early detection of oil spills and other signs of toxicity in the water [40].

\subsubsection{Target 14.4 Sustainable Fishing}

The global footprint of fishing is much larger than those of other forms of food production, even though fisheries provide only a small fraction of global caloric production for human food consumption [41]. It is estimated that fish provide 20 percent of animal protein to about 3 billion people [27]. Yet, that footprint is poorly understood and quantified. The sustainability of fisheries is essential to the livelihoods of billions of people and particularly in developing countries where the vast majority of fishermen live [49]. Considering that 152 countries are coastal countries [50], AI technologies can supplant the high cost of direct observations of fishing activity on board vessels and improve the management of and efficiency in fisheries $[23,51]$. Drones are being explored to identify and video record boats that are illegally fishing [40].

Example 5: Refind Technologies in Sweden installed an AI software in a fishing boat to help identify fish subspecies from photographs taken by the system [52]. Such automized recognition of image recognition in fisheries allows the analysis of large data volumes on removals of commercial fishing fleets, and at lower costs [24]. Several other recent AIbased systems have become reality and are poised to enable the automation of biodiversity monitoring [53], helping also in the tracking of endangered species.

Illegal, unreported, and unregulated (IUU) fishing is a major threat to marine biodiversity [54], even in marine protected areas, which are set up to help fish stocks recover from prior over-exploitation [51]. IUU represents a major cost for society as a whole [51] and a huge global challenge. The achievement of target 14.4 is directly linked to target 14.6, i.e., end subsidies contributing to overfishing [50].

Example 6: Satlink, a Spanish startup, is using AI to collect data on catchments and releases to hold fishing boats accountable to their catches and quotas [40].

Blockchains can help combat IUU fishing and sustainability of marine ecosystems by improving traceability from "bait to plate", to help address illegal fishing [54]. The nature of the technology is such that the data in the blockchain are, with some caveats, tamper proof, and blockchain is self-organizing across jurisdictional borders and institutional responsibilities [24]. This is important as the issues of oceans are transboundary in nature. They require global policies, commitments, and management from public and private actors to make progress [5].

Some believe that blockchain will become the industry standard for transparency and traceability in fisheries [54]. Fishcoin has even become a moniker to refer to blockchainbased seafood traceability [55]. Yet, maintaining blockchains in near real-time requires communication infrastructure, such as satellite communication, appropriate bandwidth and stable network connections, which might prove challenging, not to mention cost prohibitive for small-scale fisheries [24]. It would be naive to think that blockchain, data mining, and AI will eradicate IUU fishing. However, these examples demonstrate that technology can improve compliance to laws and regulations and help consumers make better informed purchasing decisions [5,24], which is SDG 12, Responsible consumption and Production. SDGs and targets are challenges that offer a multitude of entrepreneurial opportunities as evidenced by the following examples.

Example 7: Provenance, a UK-based company, applies blockchain to create end-toend transparency in supply chains, including fishing products [56]. This contributes to sustainability and food safety related to fish. 
Example 8: OpenSC, a collaborative venture, has developed a supply chain transparency platform based on blockchain to verify and trace large amounts of Patagonian tooth fish and prawns [54].

\subsubsection{Target 14.5 Conserve Coastal and Marine Areas}

Coral reefs form the life system of the ocean, yet they are some of the most threatened ecosystems on the planet. Currently, 75 percent of the world's coral reefs are threatened [57]. Reefs play a key life nurturing role as an ecosystem, with 25 percent of all marine life depending on coral reefs [57] and half a billion people depending on reefs for their livelihood [57].

Example 9: CoralNet is a web-based AI resource that analyzes coral reefs, using deep neural networks that allow annotation of images. This open-source application serves as a data repository and a collaboration platform [58].

Example 10: Similarly, CORail is an international partnership including Intel, Accenture and the Sulubaai Environmental Foundation (Philippines) to collect reef data using AI-driven video analytics, cameras fitted in the ocean, and continuous and non-invasive monitoring to assist researchers determine strategies to protect reefs [33].

\subsection{AI Applications to Achieve SDG 15-Life on Land}

SDG 15 aims to tackle issues of deforestation, land degradation and desertification, which cause loss of biodiversity, and to eliminate poaching and trafficking of protected species, as well as prevent invasive alien species [2]. The loss of forests and biodiversity is staggering. It is estimated that one million animal and plant species are facing extinction, equaling to 22 percent of known animal species. Forests are the habitat of most terrestrial animals, plants, and insects. Forests also combat climate owing to their carbon sink capacity, that is, absorbing more carbon than it releases. Managing forests sustainably could increase their capacity to remove human-produced carbon dioxide from the atmosphere, hence reducing greenhouse gas emissions [2]. AI technologies can help address SDG 15 targets, and we are looking at solutions for the related targets 15.2, 15.3, 15.5, 15.7 and 15.8.

Considerations for studying deforestation include identifying the factors that affect it, predicting where deforestation will occur, and predicting how much forest will be lost. These considerations involve a large number of interrelated variables that are well suited to using more advanced machine learning models and deep learning, using a variety of available datasets [59].

\subsubsection{Target 15.2 Promote Sustainable Management Forests}

Deforestation has increased in speed and intensity in the important Amazon rainforest due to numerous factors, including migrant occupation of rural lands, mineral exploration, and timber extraction. The deforestation creates negative impacts on Brazil's biodiversity [60]. AI approaches can help. For example, AI can analyze satellite data and ground-based sensors to monitor forest conditions and detect activities such as illegal deforestation [20].

Example 11: Leal et al. [60] show that AI and, more specifically, artificial neural networks (ANN) can successfully estimate the deforestation rates by rural property, hence showing the high potential of ANN as a tool to estimate deforestation rates.

In the Amazon rainforest, machine learning is used to demonstrate the significant influence on the deforestation process of regular roadway network and clandestine roadway network in the last 30 years [61].

Example 12: ForestNet is a deep learning model developed to automatically identify and classify the drivers of primary forest loss in Indonesia, using satellite imagery [62]. Indonesia suffers one of the highest deforestation rates in the world, hence the role of deforestation in its emissions profile is significantly larger than the rest of the world [63].

Example 13: NASA is using machine learning algorithms and supercomputers to map non-forest trees across a wide area to calculate how much carbon they store. The aim of the 
project is to enhance understanding of Earth's carbon cycle and how it is changing over time [64].

\subsubsection{Target 15.3 Achieve Land Degradation Neutrality}

A number of trends are resulting in land degradation, defined as the reduction or loss of the biological or economic productivity of land [65]. These trends include unsustainable land use management strategies, population growth, and urbanization, and are affecting the well-being of billions of people [66]. Taken together, land degradation and desertification affect over half of the land used for agriculture globally [29]. Deforestation and climate change contribute to soil degradation [29].

Example 14: Researchers from the University of Geneva in collaboration with researchers from the National Research Council of Italy, the European commission and the European Space Agency have developed a knowledge-generation system to address the challenge of inadequate mapping and monitoring of land degradation changes at the national scale. Building on Trends.Earth, an online platform that monitors land degradation using satellite imagery and global data, itself a relatively new tool [65], the proof-of-concept is a scalable and flexible framework to monitor land degradation at different geographical scales, to support evidence-based policymaking [66].

\subsubsection{Target 15.5 Reduce Degradation of Natural Habitats, Halt Loss of Biodiversity}

SDG 15 targets are all connected: the main key threats affecting biodiversity are human activities, loss of habitat, deforestation, desertification, climate change, overharvesting, and introduction of invasive alien species (IAS). Here, again, AI technologies can support the achievements of SDG 15.

Example 15: Wildbook, a browser-based tool, is an example of automated identification that uses neural networks and computer-vision algorithms to detect and count animals in images, and to identify these animals within a species, allowing a more precise estimate of wildlife population sizes [52], especially regarding endangered species.

Example 16: Conservation Metrics, a California firm that uses AI to assist wildlife monitoring, applied AI to audio files representing 25 days' worth of recordings of birds colliding with powerlines to measure the number of bird deaths. The system found a much higher number of deaths than expected, motivating researchers to work with the power utility of the studied geographical area to come up with solutions to this issue [52].

\subsubsection{Target 15.7 End Trafficking of Protected Species}

Only 3200 tigers are left from more than 60,000 a century ago [67]. Elephants, rhinos and scores of other wild animal species are threatened by extinction due to poaching, which is a growing problem. Gloomily, the number of poached rhinos in South Africa increased from 13 in 2007 to 1215 in 2014 [68]. A substantial amount of poaching occurs within huge nature preserves of some million and more hectares $[67,69]$. Working on such extensive areas, rangers tasked with protecting endangered wildlife are constantly outnumbered by poachers, given that this lucrative illegal industry is estimated to be worth USD 7 billion [69]. Many countries depend heavily on tourism and visits to protected areas and national parks. Fewer animals also mean fewer tourists, hence less funding to protect these areas and pay park rangers [68], further compounding the problem.

Example 17: Wildlife Protection Solutions (WPS), a nonprofit, is using machine learning and a network of motion detectors and cameras to identify more poachers and at a faster pace than ever before using only remote monitoring. The system is estimated to be twice as effective as previous non-machine learning approaches and is constantly improving with more data.

Example 18: Protection Assistant for Wildlife Security (PAWS) is an AI-driven system developed by researchers at the University of Southern California that incorporates game theory applied to wildlife protection [67]. With data such as patrol activity and poaching signaling and topographical data, PAWS plans routes for rangers that maximize poacher 
apprehension while minimizing wildlife risk. As a learning system, more data provides better outcomes against poaching. PAWS has been successfully implemented in Uganda and Malaysia, and is also being enhanced to improve its accuracy for efficient patrols to combat poaching [67].

Example 19: Archangel Imaging, a UK-based start-up, is using AI and satellite communications to tackle wildlife poaching in protested areas and national parts using technology first developed by ESA Space Solutions. The system has cut response times to sightings of poachers from a couple of hours down to minutes. When a poacher is detected by the system, an alert is sent to the nearest park range or a drone. Space technology has allowed the deployment of off-grid AI monitoring [68].

\subsubsection{Target 15.8 Reduce the Impact of Invasive Alien Species}

Invasive alien species (IAS) are plants, animals, pathogens, and other organisms that are non-native to an ecosystem. Often, IAS have been introduced by humans into places where they do not belong. These species compete with native species and adversely impact biodiversity and disrupt ecosystem functions. IAS are considered one of the greatest threats to biodiversity and these invasions are accelerating worldwide. Since the 17th century, IAS have contributed to nearly 40 percent of all animal extinctions for which the cause of death is known [70]. In addition to the threat to biodiversity, IAS exacerbate poverty due to their impact on agriculture, forestry, fisheries, and natural systems [70,71]. Sadly, the damage is also aggravated by climate change, pollution, habitat loss and human activities [70].

Example 20: Jensen et al. [71] tested the performance of various machine learning algorithms, using remote sensing data on Kudzu vine, an invasive plant that originated from East Asia and quickly outcompeted native plants in parts of the US. The goal of the study is to enhance the automatic detection of invasive plant species in given geographic areas.

Example 21: Carter et al. [72] have developed and tested a rapid machine-learning approach that can provide data-driven management information for early detection of potential invaders.

Example 22: Robots can help reduce the threat of invasive species. For example, robot predators are being designed in controlled environments by researchers from UWA and New York University to combat mosquitofish, listed as one of the worst IAS owing to their ability to survive about anywhere, hence creating huge impacts on biodiversity as they outcompete native species [73].

The use of machine learning and deep learning and the development of maps of IAS have increased in recent years. However, the development and testing of machine learning models can be complex and time consuming. AI and machine learning require not only computing power but large amount of training data, which, for endangered species, might be challenging if not impossible to collect. Human input is still needed [52]. That said, open-source programs allow users to export training data and use libraries to create machine-learning models [52]. Another challenge is the nonuniversal access to very large datasets and computer power required to use them, which might negatively impact the use of AI for SDGs [1]. Hence, the use of AI to reduce deforestation, for instance, is considered a major challenge in the least developed countries [4].

\section{Framework and Discussion}

Drawing from these recent examples of applications of AI and AI-driven robotics to various domains of wildlife and land conservations under SDGs 14 and 15, we now turn to the development of a conceptual framework to categorize these AI applications and opportunities with a view to portray the state of advancement of AI to contribute to SDGs 14 and 15 and observe the gaps and research opportunities.

\section{1. $M^{3}$ Framework for AI Applications to Achieve SDGs 14 and 15}

The framework is a 2-by-3 matrix that reflects the state of the technology's development and the focus of the application. Specifically, the states are determined as: 
Current: the components of the overall AI-enabled system are based on existing technologies already in use in wildlife and land conservation.

Emerging: one or several components of the overall AI-enabled system are based on new and promising science and technology such that the overall system is more experimental in nature for wildlife, ocean and land conservation, with applications generally falling in the range of proof-of-concepts and feasibility studies.

The focus of the applications is the context of AI-enabled applications to SDGs, defined as:

Measure: refers to capability of AI-enabled systems to count, estimate, detect, map, identify, or classify parameters of interest.

Monitor: refers to the automated capability of AI-enabled systems to assess and follow the evolution of parameters of interest.

Mitigate: refers to the capability of AI-enabled systems to contribute to harm reduction from threats to wildlife and land conservation.

The Measure-Monitor-Mitigate framework or $\mathrm{M}^{3}$ framework represents a continuum from simpler to increasingly more sophisticated capabilities of AI-enabled systems to help address SDGs 14 and 15 targets.

Table 3 summarizes the previously discussed examples using the framework axes in pursuance of placing the AI systems into various cells of our framework.

Table 3. Summary of examples of AI-enabled systems for selected SDGs 14 and 15 targets. Developed by authors in 2021.

\begin{tabular}{|c|c|c|c|c|}
\hline SDG Target & Example & AI System & $\begin{array}{c}\text { State of } \\
\text { Technology }\end{array}$ & $\begin{array}{c}\text { Focus of } \\
\text { Application }\end{array}$ \\
\hline \multirow{3}{*}{14.1} & 1 & MARLIT & Emerging & Measure \\
\hline & 2 & Ocean Cleanup & Emerging & Mitigate \\
\hline & 3 & Micro-robots & Emerging & Mitigate \\
\hline 14.2 & 4 & IBM & Emerging & Measure \\
\hline \multirow{4}{*}{14.4} & 5 & Refind Tech. & Current & Measure \\
\hline & 6 & Satlink & Current & Monitor \\
\hline & 7 & Provenance & Emerging & Monitor \\
\hline & 8 & OpenSC & Emerging & Monitor \\
\hline \multirow{2}{*}{14.5} & 9 & CoralNet & Current & Measure \\
\hline & 10 & CORail & Current & Measure \\
\hline \multirow{3}{*}{15.2} & 11 & Leal et al. & Current & Measure \\
\hline & 12 & ForestNet & Emerging & Measure \\
\hline & 13 & NASA & Emerging & Measure \\
\hline 15.3 & 14 & U of Geneva & Emerging & Monitor \\
\hline \multirow{2}{*}{15.5} & 15 & Wildbook & Current & Measure \\
\hline & 16 & Conservation Metrics & Current & Measure \\
\hline \multirow{3}{*}{15.7} & 17 & WPS & Current & Monitor \\
\hline & 18 & PAWS & Emerging & Monitor \\
\hline & 19 & Archangel Imaging & Emerging & Monitor \\
\hline \multirow{3}{*}{15.8} & 20 & Jensen et al. & Emerging & Measure \\
\hline & 21 & Carter et al. & Current & Measure \\
\hline & 22 & UWA, NYU & Emerging & Mitigate \\
\hline
\end{tabular}

Based on a summary of the examples shown in Table 3, we now map them onto our framework shown in Figure 2. 


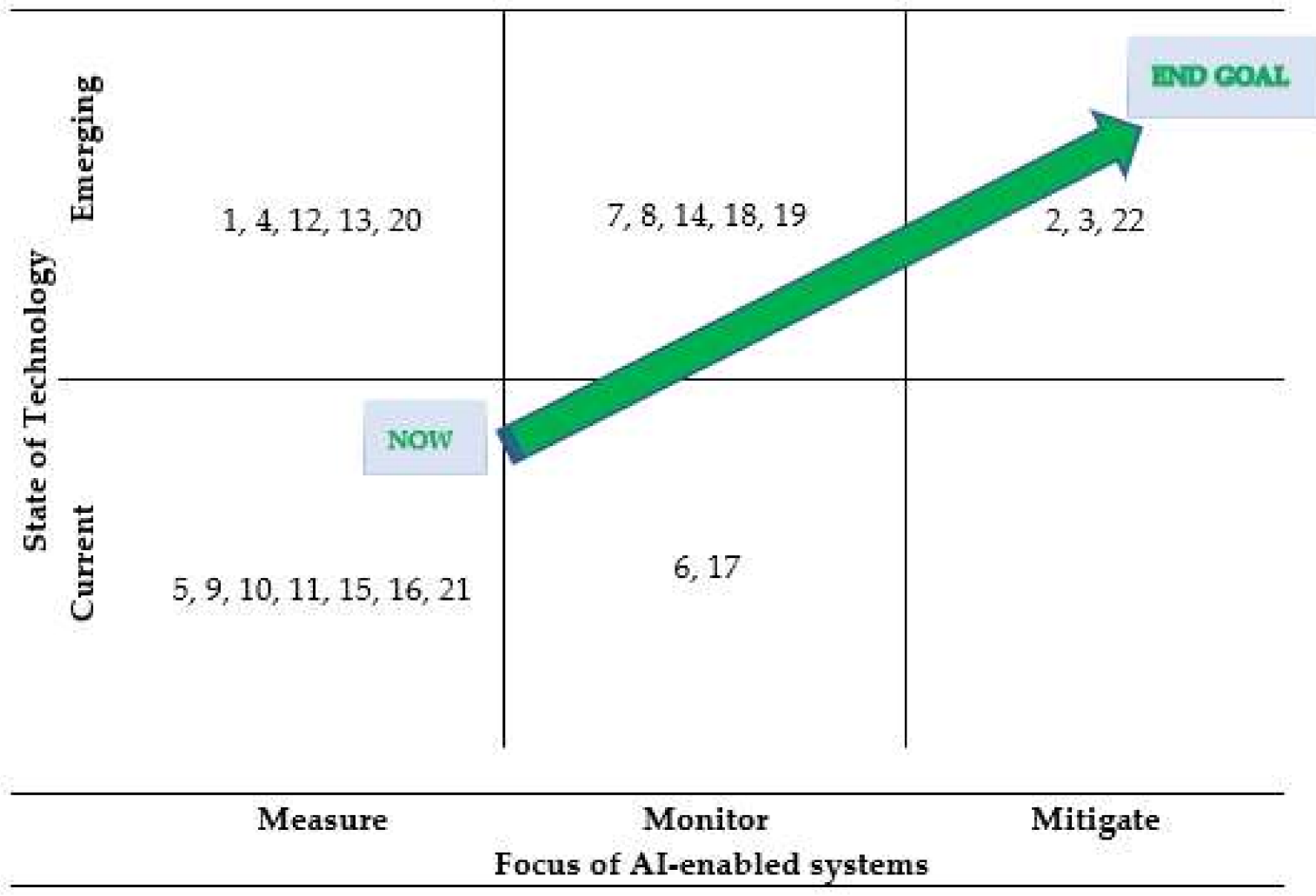

Figure 2. Examples mapped on $\mathrm{M}^{3}$ Framework. Figure developed by the authors 2021.

Our framework comprises six cells based on the state of AI technology and the focus of AI-enabled systems for our recent AI application examples to help address selected targets of SDGs 14 and 15. The obvious first observation is the empty Current-Mitigate cell. This finding suggests that the current knowledge and applications of AI and complementary technologies do not extend to mitigating, that is, do not contribute to harm reduction from threats to wildlife and land conservation. This is an important contribution of this study. It shows that without a concerted push to accelerate the development of AI, its applications would essentially linger at measuring and monitoring threats without reaching its potential as a key component of a science-based approach to achieve SDG targets.

Referring back to PwC's study on forms of AI intelligence [31], the results from our literature searches and selected examples of emerging practices in AI-based approaches to SDGs 14 and 15 show that most current AI applications in the various domains of wildlife, ocean and land conservation would fall under "assisted" or "augmented" intelligence rather than "automation" or "autonomous" intelligence. Likewise, using PwC's report on the mapping of some 345 technology applications across the SDGs [36], most of the AI technologies used in our examples are more likely to fall under "high" maturity with some under "medium" maturity than under "low" maturity.

\subsection{Getting from "Now" to "End Goal"}

Our review of the literature revealed that SDGs 14 and 15 are currently languishing at the bottom of priorities by countries and industry alike and are not receiving the attention that is urgently required for nature and humanity.

The arrow on our framework indicates that the path that is required to move from where most of AI applications tend to be now, that is, in the Current-Measure cell, to the end goal of Emerging-Mitigate cell. With over 60 years of development and rapid advances in recent years [10], undoubtedly, there will be a better and larger variety of solutions in the ever-evolving domain of AI to help achieve SDG targets. However, these 
solutions cannot be developed in isolation. In effect, various frontier technologies such as blockchain, IoT, and robotics work in tandem with AI to result in better performing systems that can also be adapted to a broader range of wildlife, ocean and land conservation challenges. Our examples in the "emerging" cells and particularly those in the "end goal" cell demonstrate this.

Vinuesa et al. [7] raise the possibility that AI could analyze large-scale interconnected databases to support evidence-based decision making related to SDGs and the environment (SDGs 13, 14 and 15). On that note though, AI benefits for some SDGs might turn out to be disadvantages for others, or enablers/inhibitors also raised by Vinuesa et al. [7]. For instance, high energy data centers to run blockchains aimed at helping to achieve targets under SDGs 14 and 15 such as the Fishcoin blockchain application from our examples could have a detrimental effect on targets under SDG 13, Climate Action, particularly depending on the nature of the energy source used to run such data centers. In that vein, Microsoft is exploring the feasibility of subsea datacenters powered by renewable energy, on-shore wind and solar, off-shore tide and wave, with Project Natick, a deployment of a full-scale datacenter module in the North Sea [74,75].

$\mathrm{AI}$ and complementary technologies alone will not resolve the threats to life below ocean and life on land. An exhaustive analysis of other enabling factors, barriers and challenges to overcome so that AI advances can be adequately embedded into decision-making processes is outside the scope of this study. However, suffice it to mention institutional barriers, safety, ethics of AI, misuse of AI-related information, digital surveillance and privacy, legislation related to transparency and accountability of AI, Green AI, regulatory insight and oversight, and insufficient integration of science with regulatory authorities $[5-7,66,76,77]$.

\subsection{Entrepreneurial Opportunities}

Through our literature searches and exploration of AI-based approaches to contribute toward SDGs 14 and 15, we observe that emerging AI systems are primarily at the research, proof-of concept stage, within universities, often in conjunction with research centers. Conversely, we observed that some of the new discoveries led to the formation of new ventures, such as OpenSC, a venture co-founded by WWF and BCG Digital Ventures [54].

International scientific collaboration to achieve scientific progress is a well-discussed mechanism in the literature $[78,79]$. On that note, it is uplifting to observe the numerous ISCs related to SDGs in our study and selected examples. This is in line with Payumo et al.'s [80] mapping of collaborations and partnerships in SDG research, which shows an increased collaboration rate, particularly at the institutional level and in the US, the UK, and Europe. Careful considerations of inclusive innovation [81] must be at the forefront to address the AI divide between developed and developing nations and resulting inequalities $[7,13,15,82]$.

Commercialization of science and technology from universities and research centers, including knowledge and technology transfer to business, is a long and arduous process fraught with obstacles [83]. Scalability is often the next step in current AI-enabled systems for SDGs 14 and 15. Therefore, SDGs can become a catalyst for innovation for business, small and large [6] and cross-industry collaboration [5]. Enabled by strong leadership and embedded in business strategic goals, engagement with SDGs can lead to fruitful collaborative research partnerships and technology transfer opportunities for entrepreneurs to scale up and commercialize emerging AI-enabled technology solutions for planet, people and profits, using sustainable business models [84]. Recent applications and opportunities for further cross-sectoral and cross-industry collaboration include the use of machine learning to model an environmental system such as an aquatic ecosystem to forecast its behavior, analyze its capability to react to natural or human-induced disturbances and unforeseen events, and provide decision-making aid to implement suitable measures to protect it $[85,86]$. Likewise, the application of AI methods or models in a specific context, for instance the application of deep learning and meta-transfer model to make predictions in one aquatic habitat based on a model developed in another aquatic habitat [86]. Another 
area includes beneficial symbiotic human-robot collaboration, as it allows for robots to take care of both dangerous and harmful tasks and tasks that require accuracy and care [87-89].

It is indisputable that the private sector must and can play a key role in developing and commercializing innovative products and services that will contribute to achieving SDGs. That said, the academic literature mentions the need to better understand the role of business in addressing SDGs [16]. A case in point, Mio et al.'s [16] systematic literature review of SDGs and the strategic role of business found that among industries, mining, banking, fishing, and tourism industries were most investigated in academic studies about businesses and SDGs. As for specific SDGs, they compared academic research with evidence from corporate practice [6] and found that the most discussed SDG was Goal 9 (Industry, Innovation, Infrastructure). SDGs 14 and 15 were notably absent. Similarly, PwC's analysis of 1141 companies in 31 countries [6] shows that SDG 13, Climate Action, appeared in the top three goals for business in essentially all of the countries in the sample. However, SDG 14 did not. These are alarming findings. Without the role of business to help accelerate the achievements of SDGs 14 and 15, progress will be slow, which humanity cannot afford as time is running out.

Fortunately, business, and even startups can get involved. This is enabled by the fact that academic researchers, alone or in partnership with others, make their datasets, models and findings readily available to support current and future research. This is important since more open and reproducible science is essential to adequately embed science into the decision-making process and to support the development and commercialization of innovation and technologies [66]. Apparent knowledge spillovers from AI are not as widespread as expected though, as evidenced by a study in Australia [12]. Moreover, application of machine learning is now more accessible. Several organizations and companies are offering pretrained models, model development platforms and open-source models that can enable small firms and entrepreneurs to latch onto potential SDG-related opportunities. In a trust to motivate firms to become more involved in AI research for SDGs, care must be taken that the economic value does not introduce long-term threats to environmental sustainability [7].

\section{Conclusions}

This study addressed the need for a better understanding of the evolving field of AI-enabled systems to contribute to the achievements of SDGs, with a direct focus on selected targets of SDGs 14, Life below Water, and SDG 15, Life on Land. The resulting framework makes several important contributions to theory and practice.

\subsection{Theoretical Contributions}

This study echoes the insights from prior work, and that is the strong and urgent need to harness the opportunities afforded by AI and complementary technologies to help achieve SDG goals related to the environment. This is particularly so for SDGs 14 and 15 that are currently under-researched. Our $\mathrm{M}^{3}$ framework that categorizes practices in AI-based approaches to biodiversity, ocean and land conservation is based on a solid foundation of recent scholarly work.

Our findings provide scholars a much-needed taxonomy and an organizing framework to grasp the disjointed literature on $\mathrm{AI}$ and SDGs. The $\mathrm{M}^{3}$ framework can be built upon for further exploration. For instance, despite being focused on two SDGs goals and selected related targets, its application is largely transferable to other SDGs. We support Sætra's conclusion [17] that there is a need to go beyond simplistic analyses of AI applications per specific SDG. Hence, our $\mathrm{M}^{3}$ framework can be applied to further investigate the grand challenge of increasing deterioration of natural habitat and decreasing biological diversity.

\subsection{Managerial Implications}

With only a decade left to meet the global goals, business as usual is clearly not an option for government, universities, research centers, and the private sector. All stakeholders 
must take an interdisciplinary, cross-sectoral approach to work collaboratively to accelerate progress towards the SDGs. The rapid development of AI technologies can and should be harnessed to reach these goals, in a sustainable fashion.

Our framework could be adapted to map current and proposed AI policies and governance mechanisms against SDGs with a view to identify policy areas most urgently needed for beneficial AI technologies to emerge yet proactively anticipate and mitigate potential harmful impacts. This work should be coordinated at the global level for optimum impacts and speed.

Our framework could lead to a deeper understanding of potential AI-enabled business opportunities to overcome the severe implications of the SDGs 14 and 15 for global food security, nature, and humanity. Businesses can use our $\mathrm{M}^{3}$ framework to help determine where their efforts should lie to competitively bring novel products and services aligned with the "end goal" of our framework, seeking collaborators and developing sustainable business models.

\subsection{Limitations and Future Research Directions}

While we recognize that this study has its limitations and caveats, we identified relevant knowledge gaps that provide directions for future research. The analysis and interpretation of findings represent the perspective of the authors. Although we developed a rigorous methodology and conducted a comprehensive review of the literature, we might have missed articles and other material on how AI can positively contribute to the achievement of SDGs 14 and 15. Furthermore, relevant studies might not have been published yet.

Our framework concerns SDGs 14 and 15. However, SDGs are interrelated and particularly so with SDG 13, Climate Action. This represents an opportunity to incorporate AI-enabled systems for SDG 13 into our $\mathrm{M}^{3}$ framework to obtain a more comprehensive picture of the state of AI applications toward the three environmental SDGs, that is, SDGs 13,14 and 15.

Overall, the recent and accelerating development of AI technologies generates positive benefits towards the achievements of the SDGs, with further benefits yet to come [10]. This has been our perspective in this study. Realistically, harmful impacts of AI related to SDGs must be further explored, building from prior work [1,4,7] and aiming at producing more responsible AI innovation. Future research directions could also extend to ESG factors to consider AI-related ESG impacts [17]. In closing, it is our hope that our $\mathrm{M}^{3}$ framework will become a helpful tool in the quest to benefit from AI advances to combat what are conceivably the greatest challenges of the current century to our natural world.

Author Contributions: Conceptualization, D.A.I.; methodology, D.A.I. and M.W.; writing—original draft preparation, D.A.I. writing-review and editing, D.A.I. and M.W. All authors have read and agreed to the published version of the manuscript.

Funding: This research received no external funding.

Institutional Review Board Statement: Not applicable.

Informed Consent Statement: Not applicable.

Conflicts of Interest: The authors declare no conflict of interest.

\section{References}

1. Sætra, H.S. AI in Context and the Sustainable Development Goals: Factoring in the Unsustainability of the Sociotechnical System. Sustainability 2021, 13, 1738. [CrossRef]

2. AI for Good. Goal 15: Life on Land. Available online: https://ai4good.org/ai-for-sdgs/goal-15-life-on-land/ (accessed on 30 September 2021).

3. United Nations. Sustainable Development Goals. Available online: https://sdgs.un.org/goals (accessed on 30 September 2021).

4. Palomares, I.; Martínez-Cámara, E.; Montes, R.; García-Moral, P.; Chiachio, M.; Chiachio, J.; Alonso, S.; Melero, F.J.; Molina, D.; Fernández, B.; et al. A panoramic view and swot analysis of artificial intelligence for achieving the sustainable development goals by 2030: Progress and prospects. Appl. Intell. 2021, 51, 6497-6527. [CrossRef] [PubMed] 
5. World Economic Forum. Unlocking Technology for the Global Goals. Available online: https://www3.weforum.org/docs/ Unlocking_Technology_for_the_Global_Goals.pdf (accessed on 30 September 2021).

6. PwC. Creating a Strategy for a Better World. How the Sustainable Development Goals Can Provide the Framework for Business to Deliver Progress on Our Global Challenges. Available online: https://www.pwc.com/gx/en/sustainability/SDG/sdg-2019.pdf (accessed on 30 September 2021).

7. Vinuesa, R.; Azizpour, H.; Leite, I.; Balaam, M.; Dignum, V.; Domisch, S.; Felländer, A.; Langhans, S.D.; Tegmark, M.; Nerini, F.F. The role of artificial intelligence in achieving the Sustainable Development Goals. Nat. Commun. 2020, 11, 233. [CrossRef] [PubMed]

8. Di Vaio, A.; Palladino, R.; Hassan, R.; Escobar, O. Artificial intelligence and business models in the sustainable development goals perspective: A systematic literature review. J. Bus. Res. 2020, 121, 283-314. [CrossRef]

9. Goralski, M.A.; Tan, T.K. Artificial intelligence and sustainable development. Int. J. Manag. Educ. 2020, 18, 100330. [CrossRef]

10. United Nations. Resource Guide on Artificial Intelligence (AI) Strategies. Available online: https://sdgs.un.org/sites/default/ files/2021-04/Resource\%20Guide\%20on\%20AI\%20Strategies_April\%202021_rev_0.pdf (accessed on 4 October 2021).

11. Biermann, F.; Kanie, N.; Kim, R.E. Global governance by goal-setting: The novel approach of the UN Sustainable Development Goals. Curr. Opin. Environ. Sustain. 2017, 26, 26-31. [CrossRef]

12. Cetindamar, D.; Lammers, T.; Zhang, Y. Exploring the knowledge spillovers of a technology in an entrepreneurial ecosystem-The case of artificial intelligence in Sydney. Thunderbird Int. Bus. Rev. 2020, 62, 457-474. [CrossRef]

13. Cheng, Y.; Liu, H.; Wang, S.; Cui, X.; Li, Q. Global Action on SDGs: Policy Review and Outlook in a Post-Pandemic Era. Sustainability 2021, 13, 6461. [CrossRef]

14. Mabkhot, M.M.; Ferreira, P.; Maffei, A.; Podržaj, P.; Mądziel, M.; Antonelli, D.; Lanzetta, M.; Barata, J.; Boffa, E.; Finžgar, M.; et al. Mapping Industry 4.0 Enabling Technologies into United Nations Sustainability Development Goals. Sustainability 2021, 13, 2560. [CrossRef]

15. Mhlanga, D. Artificial Intelligence in the Industry 4.0, and Its Impact on Poverty, Innovation, Infrastructure Development, and the Sustainable Development Goals: Lessons from Emerging Economies? Sustainability 2021, 13, 5788. [CrossRef]

16. Mio, C.; Panfilo, S.; Blundo, B. Sustainable development goals and the strategic role of business: A systematic literature review. Bus. Strategy Environ. 2020, 29, 3220-3245. [CrossRef]

17. Sætra, H.S. A Framework for Evaluating and Disclosing the ESG Related Impacts of AI with the SDGs. Sustainability 2021, 13, 8503. [CrossRef]

18. Truby, J. Governing Artificial Intelligence to benefit the UN Sustainable Development Goals. Sustain. Dev. 2020, 28, 946-959. [CrossRef]

19. United Nations. Sustainable Development Goal 14. Available online: https://sdgs.un.org/goals/goal14 (accessed on 4 October 2021).

20. PwC. How AI Can Enable a Sustainable Future. Available online: https:/ /www.pwc.co.uk/sustainability-climate-change/assets/ pdf/how-ai-can-enable-a-sustainable-future.pdf (accessed on 4 October 2021).

21. PwC. Building Block (Chain)s for a Better Planet. Available online: https://www.pwc.com/gx/en/services/sustainability/ building-blockchains-for-the-earth.html (accessed on 4 October 2021).

22. Eddy, T.D.; Lam, V.W.; Reygondeau, G.; Cisneros-Montemayor, A.M.; Greer, K.; Palomares, M.L.D.; Bruno, J.F.; Ota, Y.; Cheung, W.W. Global decline in capacity of coral reefs to provide ecosystem services. One Earth 2021, 4, 1278-1285. [CrossRef]

23. United Nations. The Second World Ocean Assessment. Available online: https://sdgs.un.org/sites/default/files/2021-04/woaii-vol-i.pdf (accessed on 7 October 2021).

24. Probst, W.N.; Beyan, C. How emerging data technologies can increase trust and transparency in fisheries. ICES J. Mar. Sci. 2020, 77, 1286-1294. [CrossRef]

25. Majeed, S.A.A. Sustainable Development Goal (SDG 14): 'Life below Water'—Preserving and Protecting the Oceans and Seas and the Life within Them Is a Vital Task for Engineers. Available online: http://aslamsaja.com/sustainable-development-goal-sdg-14 -life-below-water-preserving-and-protecting-the-oceans-and-seas-and-the-life-within-them-is-a-vital-task-for-engineers / (accessed on 7 October 2021).

26. United Nations. Sustainable Development Goal Indicators. Available online: https://unstats.un.org/sdgs (accessed on 7 October 2021).

27. United Nations. Sustainable Development Goal 15. Available online: https://sdgs.un.org/goals/goal15 (accessed on 7 October 2021).

28. United Nations. SDG 15: Life on Land-Facts and Figures, Targets, Why It Matters. Available online: https://knowledge.unccd. int/publications/sdg-15-life-land-facts-and-figures-targets-why-it-matters (accessed on 7 October 2021).

29. PWC. SDG 15: Life on Land. Available online: https:/ /www.pwc.com/mu/en/events/CRA2019/cragoals/Goal15.pdf (accessed on 7 October 2021).

30. United Nations. SDG Indicators Metadata Repository. Available online: https://unstats.un.org/sdgs/metadata/?Text\&Goal=15 \&Target (accessed on 15 October 2021).

31. PwC. Sizing the Prize. What's the Real Value of AI for Your Business and How Can You Capitalise? Available online: https: //www.pwc.com/gx/en/issues/analytics/assets/pwc-ai-analysis-sizing-the-prize-report.pdf (accessed on 15 October 2021). 
32. Khakurel, J.; Penzenstadler, B.; Porras, J.; Knutas, A.; Zhang, W. The Rise of Artificial Intelligence under the Lens of Sustainability. Technologies 2018, 6, 100. [CrossRef]

33. Agarwala, N. Managing Marine Environmental Pollution using Artificial Intelligence. Marit. Technol. Res. 2021, 3. [CrossRef]

34. OECD. Tools for Trustworthy AI-A Framework to Compare Implementation Tools for Trustworthy AI Systems. Available online: https:/ / www.oecd-ilibrary.org/science-and-technology/tools-for-trustworthy-ai_008232ec-en (accessed on 2 November 2021).

35. Schillo, R.S.; Robinson, R.M. Inclusive Innovation in Developed Countries-The Who, What, Why, and How. Technol. Innov. Manag. Rev. 2017, 7, 34-46. [CrossRef]

36. PwC. Exploring 4IR-Enabled Applications for the SDGs. Available online: https://www.pwc.com/gx/en/sustainability/SDG/ 4ir-enabled-applications-for-sdgs.pdf (accessed on 2 November 2021).

37. Baumeister, R.F.; Leary, M.R. Writing Narrative Literature Reviews. Rev. Gen. Psychol. 1997, 1, 311-320. [CrossRef]

38. Rumrill, P.D., Jr.; Fitzgerald, S.M. Using narrative literature reviews to build a scientific knowledge base. Work 2001, 16, 165-170.

39. ITUNews. Conserving the 'Blue Economy' with Ocean Science and New Technologies. Available online: https:/ / news.itu.int/ conserving-oceans-ocean-science/ (accessed on 5 November 2021).

40. Sustainia. AI Can Bring New Wave of Ocean Discoveries. Available online: https://sustainiaworld.com/ai-ocean-discoveries/ (accessed on 5 November 2021).

41. Kroodsma, D.A.; Mayorga, J.; Hochberg, T.; Miller, N.A.; Boerder, K.; Ferretti, F.; Wilson, A.; Bergman, B.; White, T.D.; Block, B.A.; et al. Tracking the global footprint of fisheries. Science 2018, 359, 904-908. [CrossRef] [PubMed]

42. United Nations Environment Programme. Making Peace with Nature. A Scientific Blueprint to Tackle the Climate, Biodiversity and Pollution Emergencies. Available online: https://sdgs.un.org/sites/default/files/2021-04/Publication\%20-\%20Making\%20 Peace $\% 20$ with $\% 20$ Nature $\% 20$ A $\% 20$ scientific $\% 20$ blueprint $\% 20$ to $\% 20$ tackle $\% 20$ the $\% 20$ climate $\% 2$ C $\% 20$ biodiversity $\% 20$ and $\% 20$ pollution\%20emergencies.pdf (accessed on 7 November 2021).

43. Garcia-Garin, O.; Monleón-Getino, T.; López-Brosa, P.; Borrell, A.; Aguilar, A.; Borja-Robalino, R.; Cardona, L.; Vighi, M. Automatic detection and quantification of floating marine macro-litter in aerial images: Introducing a novel deep learning approach connected to a web application, R. Environ. Pollut. 2021, 273, 116490. [CrossRef] [PubMed]

44. Wolf, M.; Berg, K.V.D.; Garaba, S.P.; Gnann, N.; Sattler, K.; Stahl, F.; Zielinski, O. Machine learning for aquatic plastic litter detection, classification and quantification (APLASTIC-Q). Environ. Res. Lett. 2020, 15, 114042. [CrossRef]

45. Azorobotics. How AI Can Help in Detecting Marine Litter. Available online: https://www.azorobotics.com/News.aspx?newsID= 11989 (accessed on 13 November 2021).

46. Meyer, R. The Ocean Cleanup Successfully Collects Ocean Plastic, Aims to Scale Design. Available online: https: / / news.mongabay. com/2019/10/the-ocean-cleanup-successfully-collects-ocean-plastic-aims-to-scale-design/ (accessed on 13 November 2021).

47. Beladi-Mousavi, S.M.; Hermanová, S.; Ying, Y.; Plutnar, J.; Pumera, M. A Maze in Plastic Wastes: Autonomous Motile Photocatalytic Microrobots against Microplastics. ACS Appl. Mater. Interfaces 2021, 13, 25102-25110. [CrossRef] [PubMed]

48. IBM. Pioneering Microscopic Reality with New AI-Powered Microscopes. Available online: https://research.ibm.com/blog/ microscopic-reality-ai-microscopes (accessed on 26 November 2021).

49. World Economic Forum. 90\% of Fish Stocks Are Used Up-Fisheries Subsidies Must Stop Emptying the Ocean. Available online: https:/ / www.weforum.org/agenda/2018/07 / fish-stocks-are-used-up-fisheries-subsidies-must-stop (accessed on 26 November 2021).

50. IISD. IUU Index Finds World off Track on SDG Targets 14.4 and 14.6. Available online: https://sdg.iisd.org/news/iuu-indexfinds-world-off-track-on-sdg-targets-14-4-and-14-6/ (accessed on 26 November 2021).

51. Kourantidou, M. Artificial Intelligence Makes Fishing More Sustainable by Tracking Illegal Activity. Available online: https: / / theconversation.com/artificial-intelligence-makes-fishing-more-sustainable-by-tracking-illegal-activity-115883 (accessed on 26 November 2021).

52. Kwok, R. AI empowers conservation biology. Nature 2019, 567, 133-135. [CrossRef]

53. The University of Auckland. AI Is a Promising New Tool for Monitoring Marine Biodiversity. Available online: https://www. oceansofbiodiversity.auckland.ac.nz/2020/06/22/ai-is-a-promising-new-tool-for-monitoring-marine-biodiversity/ (accessed on 26 November 2021).

54. World Economic Forum. Blockchain Could Police the Fishing Industry-Here's How. Available online: https:/ /www.weforum. org/agenda/2020/02/blockchain-tuna-sustainability-fisheries-food-security/ (accessed on 26 November 2021).

55. Fishcoin. Seafood Traceability Powered by Blockchain. Available online: https://fishcoin.co (accessed on 3 December 2021).

56. Provenance. Princes Group Is Turning Tuna Sourcing Data into Brand Value. Available online: https://www.provenance.org/ case-studies/princes-tuna (accessed on 5 December 2021).

57. Coral Reef Alliance. Reef Threats. Available online: https://coral.org/en/coral-reefs-101/reef-threats/ (accessed on 5 December 2021).

58. CoralNet. A Web Solution for Coral Reef Analysis. Available online: https:// coralnet.ucsd.edu (accessed on 5 December 2021).

59. Mayfield, H.; Smith, C.; Gallagher, M.; Hockings, M. Considerations for selecting a machine learning technique for predicting deforestation. Environ. Model. Softw. 2020, 131, 104741. [CrossRef]

60. Leal, F.A.; Miguel, E.P.; Matricardi, E.A.T. Estimates of Deforestation Rates in Rural Properties in the Legal Amazon. Floresta Ambiente 2020, 27. [CrossRef] 
61. Blanco, C.J.C.; Duarte, A.A.A.M.; das Neves, F.B.S.; das Neves, I.B.S.; dos Santos, M.H.D.P. Amazon rainforest deforestation influenced by clandestine and regular roadway network. Land Use Policy 2021, 108, 105510.

62. Irvin, J.; Sheng, H.; Ramachandran, N.; Johnson-Yu, S.; Zhou, S.; Story, K.; Rustowicz, R.; Elsworth, C.; Austin, K.; Ng, A.Y. ForestNet- Classifying Drivers of Deforestation in Indonesia using Deep Learning on Satellite Imagery. In Proceedings of the 34th Conference on Neural Information Processing Systems (NeurIPS 2020), Vancouver, BC, Canada, 6-12 December 2020.

63. Republic of Indonesia. Third National Communication under the United Nations Framework Convention on Climate Change. Available online: https://unfccc.int/sites/default/files/resource/8360571_Indonesia-NC3-2-Third\%20National\%20 Communication\%20-\%20Indonesia\%20-\%20editorial\%20refinement\%2013022018.pdf (accessed on 7 December 2021).

64. NASA. NASA Supercomputing Study Breaks Ground for Tree Mapping, Carbon Research. Available online: https://www. nasa.gov/feature/goddard/2020/nasa-supercomputing-study-breaks-ground-for-tree-mapping-carbon-research (accessed on 7 December 2021).

65. Conservation International. Trends Earth, a New Tool to Assess the Health of the Land That Supports Us. Available online: https:/ / www.conservation.org/about/trends-earth (accessed on 7 December 2021).

66. Giuliani, G.; Mazzetti, P.; Santoro, M.; Nativi, S.; van Bemmelen, J.; Colangeli, G.; Lehmann, A. Knowledge generation using satellite earth observations to support sustainable development goals (SDG): A use case on Land degradation. Int. J. Appl. Earth Obs. Geoinf. 2020, 88, 102068. [CrossRef]

67. ZME Science. How AI and Game Theory Is Fighting Poaching and Illegal Logging. Available online: https://www.zmescience. com/science/news-science/artificial-intelligence-poaching-logging/ (accessed on 10 December 2021).

68. ESA Space Solutions. Using AI and Satellites to Combat Poaching of Endangered Species. Available online: https://business.esa. $\mathrm{int} /$ news/using-ai-and-satellites-to-combat-poaching-endangered-species (accessed on 10 December 2021).

69. Kaiser, C. Catching Poachers with Machine Learning. Available online: https://towardsdatascience.com/catching-poacherswith-machine-learning-118eec41d5b9 (accessed on 10 December 2021).

70. Convention on Biological Diversity. What Are Invasive Alien Species? Available online: https://www.cbd.int/idb/2009/about/ what/ (accessed on 12 December 2021).

71. Jensen, T.; Hass, F.S.; Akbar, M.S.; Petersen, P.H.; Arsanjani, J.J. Employing Machine Learning for Detection of Invasive Species using Sentinel-2 and AVIRIS Data: The Case of Kudzu in the United States. Sustainability 2020, 12, 3544. [CrossRef]

72. Carter, S.; van Rees, C.B.; Hand, B.K.; Muhlfeld, C.C.; Luikart, G.; Kimball, J.S. Testing a Generalizable Machine Learning Workflow for Aquatic Invasive Species on Rainbow Trout (Oncorhynchus mykiss) in Northwest Montana. Front. Big Data 2021, 4, 734990. [CrossRef] [PubMed]

73. Phys.Org. Robot vs. Alien: The Freshwater Fish Saga. Available online: https://phys.org/news/2020-07-robot-alien-freshwaterfish-saga.html (accessed on 12 December 2021).

74. Microsoft. Project Natick. Available online: https:// natick.research.microsoft.com (accessed on 12 December 2021).

75. Simon, K. Project Natick-Microsoft's Self-sufficient Underwater Datacenters. IndraStra Glob. 2018, 4, 1-4.

76. Westerlund, M.; Isabelle, D.A.; Leminen, S. The Acceptance of Digital Surveillance in an Age of Big Data. Technol. Innov. Manag. Rev. 2021, 11, 32-44. [CrossRef]

77. Deloitte. Green AI: How Can AI Solve Sustainability Challenges? Available online: https://www2.deloitte.com/uk/en/blog/ experience-analytics/2020/green-ai-how-can-ai-solve-sustainability-challenges.html (accessed on 15 December 2021).

78. Wagner, C.S.; Whetsell, T.A.; Leydesdorff, L. Growth of International Collaboration in Science-Revisiting Six Specialties. Scientometrics 2017, 110, 1633-1652. [CrossRef]

79. Isabelle, D.A.; Heslop, L.A. Managing for Success in International Scientific Collaborations: Views from Canadian Government Senior Science Managers. Sci. Public Policy 2011, 38, 349-364. [CrossRef]

80. Payumo, J.; He, G.; Manjunatha, A.C.; Higgins, D.; Calvert, S. Mapping Collaborations and Partnerships in SDG Research. Front. Res. Metr. Anal. 2021, 5, 612442. [CrossRef] [PubMed]

81. Grimes, H.D.; Payumo, J.G.; Fatland, A. Managing clean technology research, development, and commercialization: Success stories and lessons learned from Washington State University. In Proceedings of the PICMET'12: Technology Management for Emerging Technologies, Vancouver, BC, Canada, 29 July-2 August 2012.

82. World Economic Forum. Could Artificial Intelligence Widen the Gap between Rich and Poor Nations? Available online: https: / / www.weforum.org/agenda/2020/12/artificial-intelligence-widen-gap-rich-developing-nations (accessed on 15 December 2021).

83. Isabelle, D.A. S\&T Commercialization Strategies and Practices. In Handbook on Techno-Entrepreneurship; Thérin, F., Ed.; Edward Elgar: Abingdon, UK, 2007; pp. 63-83.

84. Isabelle, D.A. Capitalization of Science \& Technology Knowledge: Practices, Trends and Impacts on Techno-Entrepreneurship. In Handbook on Techno-Entrepreneurship: How Technology and Entrepreneurship Are Shaping the Development of Industries and Companies; Thérin, F., Ed.; Edward Elgar: Abingdon, UK, 2014; pp. 60-90.

85. Hanson, P.C.; Stillman, A.B.; Jia, X.; Karpatne, A.; Dugan, H.A.; Carey, C.C.; Stachelek, J.; Ward, N.K.; Zhang, Y.; Read, J.S.; et al. Predicting lake surface water phosphorus dynamics using process-guided machine learning. Ecol. Model. 2020, $430,109136$. [CrossRef]

86. Willard, J.D.; Read, J.S.; Appling, A.P.; Oliver, S.K.; Jia, X.; Kumar, V. Predicting Water Temperature Dynamics of Unmonitored Lakes with Meta-Transfer Learning. Water Resour. Res. 2021, 57, e2021WR029579. [CrossRef] 
87. Westerlund, M. The Ethical Dimensions of Public Opinion on Smart Robots. Technol. Innov. Manag. Rev. 2020, 10, 25-36. [CrossRef]

88. Colla, V.; Matino, R.; Schröder, A.; Schivalocchi, M.; Romaniello, L. Human-Centered Robotic Development in the Steel Shop: Improving Health, Safety and Digital Skills at the Workplace. Metals 2021, 11, 647. [CrossRef]

89. Tominaga, M.; Takemura, Y.; Ishii, K. Behavior selection system for human-robot cooperation using tensor SOM. J. Robot. Netw. Artif. Life 2020, 7, 81-85. [CrossRef] 